\title{
Caracterização do lenho e variação radial de Pittosporum undulatum Vent. (pau-incenso)
}

\author{
Eduardo Luiz Longui ${ }^{1,5}$, Diego Romeiro ${ }^{2}$, Morgana Tramontini da Silva ${ }^{3}$, Ariane Ribeiro ${ }^{3}$, \\ Tatiana Cestini Gouveia ${ }^{4}$, Israel Luiz de Lima ${ }^{1}$ e Sandra Monteiro Borges Florsheim ${ }^{1}$
}

Recebido: 18.03.2010; aceito: 6.01.2011

\begin{abstract}
Characterization of wood and radial variation of Pittosporum undulatum Vent. - pau-incenso). We studied the wood Pittosporum undulatum in Alberto Löfgren State Park, aiming to make its characterization, to investigate the radial variation of the anatomy and basic density and your relations and discuss the results in an ecological context. We utilized the standard methods to anatomy and wood density. The anatomical features corroborate the described for the genus, highlighting the presence of layer growth, not mentioned in the literature. The fibers diameter showed no radial variation, the other anatomical features, besides the density and vulnerability, mesomorphic and vessel grouping indexes increased toward the bark. There are positive relations between basic density and fiber wall thickness. The ecological analysis of the wood indicated that $P$. undulatum, investing more in security than in efficiency in the xylem water transport, since the values of ecological indexes are related to plants adapted to conditions of lower water availability.

Key words: basic density, Pittosporaceae, Pittosporum undulatum, radial variation, wood anatomy
\end{abstract}

RESUMO - (Caracterização do lenho e variação radial de Pittosporum undulatum Vent. - pau-incenso). Estudou-se o lenho de Pittosporum undulatum do Parque Estadual Alberto Löfgren, objetivando-se sua caracterização, investigar a variação radial da anatomia e densidade básica, suas correlações e discutir os resultados em um contexto ecológico. Empregaram-se as metodologias usuais para anatomia e densidade da madeira. As características anatômicas corroboram com o descrito para o gênero, ressalta-se a presença de camadas de crescimento, não mencionada na literatura. O diâmetro das fibras não apresentou variação radial, as demais características anatômicas, além da densidade básica e índices de vulnerabilidade, mesomorfia e agrupamento aumentaram na direção da casca. Houve relação positiva entre a densidade básica e a espessura da parede das fibras. A análise ecológica do lenho indicou, para P. undulatum, maior investimento na segurança do xilema do que na eficiência com relação ao transporte de água, uma vez que os valores dos índices ecológicos relacionam-se com plantas adaptadas a condições de menor disponibilidade hídrica.

Palavras-chave: anatomia da madeira, densidade básica, Pittosporaceae, Pittosporum undulatum,variação radial

\section{Introdução}

Conhecida popularmente no Brasil como pauincenso, Pittosporum undulatum Vent., (Pittosporaceae), é uma espécie perenifólia, com até 10 metros de altura, possui tronco tortuoso, com casca irregular, de cor parda escura e copa densa (Lorenzi et al. 2003). É uma espécie nativa da faixa costeira e montanhas do sudoeste da Austrália, e ocorre naturalmente em florestas úmidas, regiões ribeirinhas e ruderais
(Goodland \& Healey 1997). P. undulatum forma densos aglomerados que impedem o desenvolvimento de outras espécies, uma vez que apresenta grande capacidade na atração de polinizadores, o que diminui a disponibilidade desses agentes nas outras plantas. Devido a este fato possui alta produção de frutos e sementes, que em geral são dispersos por pássaros; além disso, a capacidade de regeneração é outra característica que lhe confere uma vantagem competitiva (Gleadow \& Ashton 1981, Binggeli \&

1. Instituto Florestal, Caixa Postal 1322, 02377-000 São Paulo, SP, Brasil

2. Universidade Nove de Julho, Av. Dr. Adolpho Pinto 109, 01156-050 São Paulo, SP, Brasil

3. Universidade do Estado de Santa Catarina, Centro de Ciências Agroveterinárias, Av. Luiz de Camões 2090, 88520-000 Lages, SC, Brasil

4. Faculdade de Ciências da Saúde, Rua Bartolomeu de Gusmão 86, 04111-020 São Paulo, SP, Brasil

5. Autor para correspondência: elongui@if.sp.gov.br 
Goodland 1997, Weber 2003, Lake et al. 2004).

Tais características tornaram a planta uma invasora em vários países como a Espanha (Paiva 1997), Portugal (Marchante et al. 2008) e Jamaica (Goodland \& Healey 1997). Bellingham et al. (2005) mencionam que a capacidade de invasão de $P$. undulatum é tão grande, que até mesmo distúrbios provocados por um furacão favoreceram sua expansão em florestas da Jamaica. Trabalhos ainda citam a alta eficiência fotossintética da espécie em relação às árvores nativas daquele país.

No Brasil foi introduzida para fins ornamentais, sendo usada na arborização de vias públicas, mas devido ao seu crescimento extremamente rápido, colonizou rapidamente áreas desflorestadas, transformando-se em espécie invasora em várias regiões (Blum et al. 2004, Silva et al. 2007).

Santana et al. (2008) relatam o impacto de espécies exóticas, entre elas $P$. undulatum, nas espécies nativas em áreas próximas a depósitos de resíduos domiciliares em áreas de Brasília e Goiás.

De acordo com Sipinski et al. (2009), $P$. undulatum está entre as principais espécies invasoras que impactam negativamente a Floresta de Araucárias. Resultados semelhantes foram observados por Franco et al. (2007) avaliando fragmentos florestais em Embu, SP, sugerindo que $P$. undulatum pode competir com as espécies nativas ocasionando problemas para a conservação da flora regional. Também em São Paulo, Metzger et al. (2008) observaram o risco de invasão de $P$. undulatum sobre a vegetação nativa na Reserva Florestal do Morro Grande (RFMG) em Cotia.

Como o nome pau-incenso sugere, a árvore exala um odor característico que está relacionado à sua composição química, Lago et al. (2006) mencionam que em todo mundo há um estudo extensivo sobre a composição do óleo essencial retirado das folhas e frutos de $P$. undulatum. No entanto, são raros os trabalhos sobre anatomia e densidade do lenho, como os de Metcalfe \& Chalk (1950) e Carlquist (1981) que descreveram as características do gênero e o de Hermann Nördlinger (1818-1897), mencionado por Bubner (2008) que no século XIX publicou uma série de fotos com secções transversais de diversas espécies, entre elas $P$. undulatum. Também há poucos registros sobre o uso de sua madeira, Goodland \& Healey (1996) reportam que na Jamaica a população local usa a madeira para a produção de carvão e lenha, em outros locais é empregada em artesanato na preparação de peças torneadas.

Visto que faltam estudos sobre a madeira de Pittosporum undulatum, objetivou-se realizar a caracterização do lenho, investigar a variação radial das características anatômicas e densidade básica e suas correlações, além de discutir tais características em um contexto ecológico.

\section{Material e métodos}

As árvores estudadas são provenientes do Parque Estadual Alberto Löfgren - PEAL, localizado na zona norte de São Paulo, nas coordenadas geográficas de latitude $23^{\circ} 45^{\prime} \mathrm{S}$ e longitude $46^{\circ} 36^{\prime} \mathrm{W}$ e altitude média de $775 \mathrm{~m}$. O clima é mesotérmico e úmido com verão chuvoso e inverno seco (Cwa de Köppen), os meses com temperaturas médias mais elevadas são janeiro e fevereiro, $\operatorname{com} 23^{\circ} \mathrm{C}$ e $22,8^{\circ} \mathrm{C}$, respectivamente, e os meses com temperaturas mais reduzidas são junho e julho, com $16,6{ }^{\circ} \mathrm{C}$ e $16,5^{\circ} \mathrm{C}$, respectivamente. A precipitação média anual é de $1.322 \mathrm{~mm}$ por ano (dados de 1992-2007), sendo janeiro o mês mais chuvoso com $229,8 \mathrm{~mm}$ e agosto o mês mais seco com 31,7 mm (Rossi et al. 2009). Na figura 1 apresenta-se a variação da precipitação e temperatura, bem como o extrato do balanço hídrico mensal. De acordo com Arzolla et al. (2009), a Floresta Ombrófila Densa Montana é a principal formação vegetacional do PEAL, onde também ocorrem áreas antrópicas que incluem arboretos caracterizados por talhões com plantios de uma ou mais espécies (nativas e exóticas), as árvores avaliadas neste estudo estavam localizadas em um destes talhões.

Retiraram-se amostras de quatro árvores de Pittosporum undulatum em forma de discos à altura do peito (tabela 1). A identificação da espécie foi realizada antes do corte das árvores e comprovada por meio de comparação de ramos com exsicatas do Herbário Dom Bento Pickel (SPSF) e com amostras de madeira da Xiloteca do Instituto Florestal (SPSFw). De cada disco foi desdobrada uma tira radial, em seguida retiraram-se amostras em três posições radiais (próxima à medula, intermediária e próxima à casca) para as análises anatômicas e da densidade básica (figura 2). Uma amostra de madeira de cada árvore foi depositada na Xiloteca do Instituto Florestal de São Paulo (SPSFw).

Para as análises anatômicas, de cada amostra obtiveram-se corpos-de-prova com cerca de $2 \mathrm{~cm}^{3}$ e destes foram retirados pequenos fragmentos que 

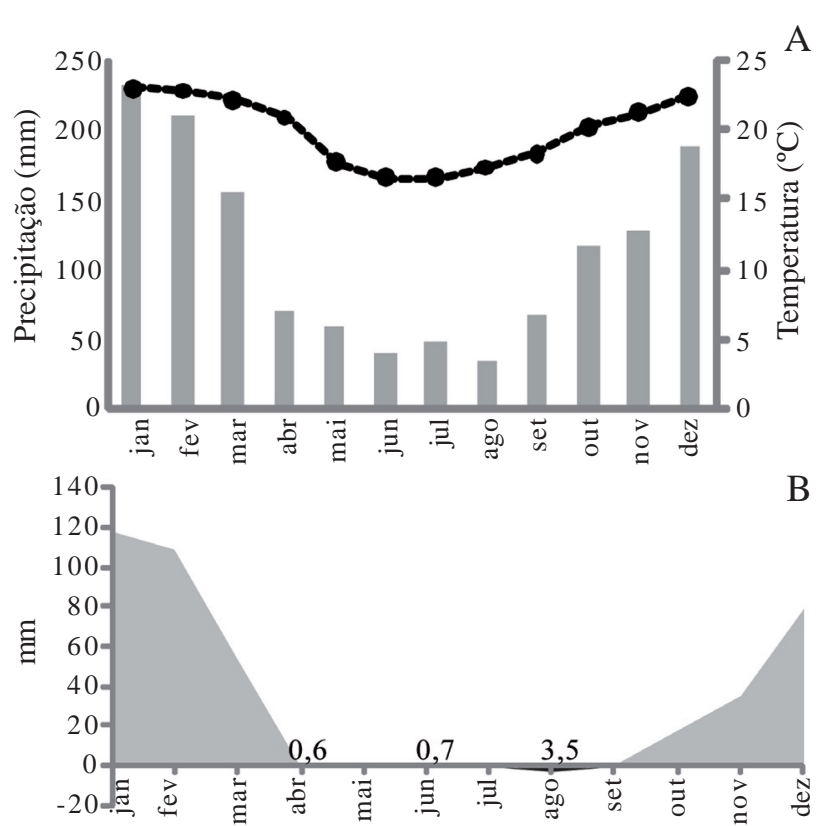

Figura 1. Caracterização climática do Parque Estadual Alberto Löfgren - PEAL. A. Variação anual da precipitação e temperatura ( $\square$ precipitação; ---•--- temperatura). B. Extrato do balanço hídrico mensal ( DEF(-1); EXC). Período de 1992-2007 (Rossi et al. 2009).

Figure 1. Describing the climate of the State Park Albert Löfgren - PEAL. A. Annual variation in precipitation and temperature ( $\square$ precipitation; --- --- temperature). B. Extract from the monthly water balance ( $\square$ DEF(-1); $\square$ EXC). Period 1992-2007 (Rossi et al. 2009).

Tabela 1. Informações sobre as árvores de Pittosporum undulatum. Table 1. Information about trees of Pittosporum undulatum.

\begin{tabular}{ccc}
\hline $\mathrm{N}^{\circ}$ Xiloteca (SPSFw) & Altura (m) & $\begin{array}{c}\text { Diâmetro a altura } \\
\text { do peito }(\mathrm{cm})\end{array}$ \\
\hline 3444 & 6,5 & 14,5 \\
3448 & 8,0 & 19,0 \\
3449 & 7,0 & 18,0 \\
3450 & 7,0 & 16,0 \\
\hline
\end{tabular}

foram macerados em solução de ácido acético e peróxido de hidrogênio 1:1 e posteriormente corados com safranina alcoólica a 1\% (Berlyn \& Miksche 1976). Para a caracterização macroscópica, os corpos-deprova foram polidos com auxílio de uma navalha, em seguida avaliados com lupa conta-fios (10x) e microscópio estereoscópico Olympus SZ61. As fotos da superfície transversal foram obtidas com câmera Evolution LC Color PL-A662 acoplada ao microscópio. Após a análise macroscópica, os mesmos corpos-deprova foram amolecidos em solução de água, álcool e glicerina em partes iguais, posteriormente seccionados

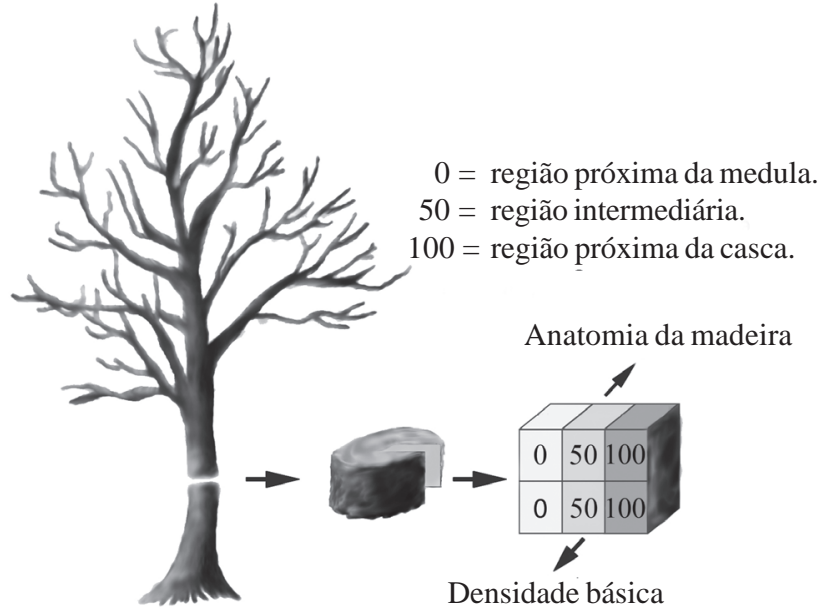

Figura 2. Representação esquemática da retirada das amostras. $\mathrm{M}=$ medula; $\mathrm{I}=$ intermediária; $\mathrm{C}=$ casca.

Figure 2. Schematic representation of sampling. $\mathrm{M}=$ pith; $\mathrm{I}=$ intermediate; $\mathrm{C}=$ bark.

em micrótomo de deslize Zeiss Hyrax S50, com espessura entre 12 e $25 \mu \mathrm{m}$. Secções de cada amostra foram clarificadas com hipoclorito de sódio a $60 \%$ e coradas com safranina $1 \%$ (Sass 1951). Prepararam-se lâminas provisórias para a análise e mensuração das seguintes características anatômicas: diâmetro e frequência de vasos e comprimento dos elementos de vaso, diâmetro das pontoações intervasculares e raiovasculares; altura, largura e frequência dos raios; comprimento, diâmetro, lume e espessura da parede das fibras, para cada característica foi adotado $n=25$, com exceção das pontoações, para as quais se adotou $\mathrm{n}=10$. As mensurações e a caracterização do lenho foram realizadas de acordo com o IAWA Committee (1989) e Coradin \& Muniz (1992). Também foi empregada análise citoquímica para a detecção de substâncias lipídicas gotejando-se Sudan IV nas secções (Johansen 1940).

A caracterização microscópica e as mensurações das células foram realizadas em microscópio marca Olympus modelo CX 31 , que conta com luz polarizada para auxiliar na distinção dos cristais e que está equipado com câmera digital Olympus EVOLT E-330 e computador com software de análise de imagens Image - Pro Plus versão 6.3. A partir dos valores anatômicos obtidos calculou-se os índices de vulnerabilidade (IV), mesomorfia (IM) e agrupamento de vasos (IAV) de acordo com Carquist (1977), para tanto foram empregadas as expressões:

$$
I V=\frac{\bar{x} D V}{\bar{x} F V} \quad I M=\frac{I V}{\bar{x} C E V} \quad I A V=\frac{\sum F V}{A V}
$$


Em que: $I V=$ índice de vulnerabilidade; $I M=$ índice de mesomorfia; $I A \mathrm{~V}=$ índice de agrupamento de vasos; $D V=$ diâmetro dos vasos; $F V=$ frequência dos vasos; $C V=$ comprimento dos elementos de vaso; $A V=$ agrupamento dos vasos (solitários, geminados, múltiplos de 3 e múltiplos de 4 ou mais).

Para densidade básica empregou-se o método da balança hidrostática segundo Foelkel (1971). Os corpos-de-prova foram saturados por dois meses para a obtenção de suas massas úmidas e imersas. Posteriormente, as mesmas foram secas em estufa até atingirem o peso de massa seca constante a $105 \pm$ $3{ }^{\circ} \mathrm{C}$.

A partir dos valores obtidos foi empregada a expressão:

$$
D B=\frac{M s}{M u-M i}
$$

Em que: $D B=$ densidade básica $\left(\mathrm{g} \mathrm{cm}^{-3}\right)$; $M_{s}=$ massa da madeira seca, a $0 \%$ de umidade $(\mathrm{g})$; $M_{u}=$ massa da madeira úmida $(\mathrm{g})$; e $M_{i}=$ massa da madeira imersa $(\mathrm{g})$.

Para auxiliar na caracterização da madeira realizou-se análise descritiva considerando as três posições radiais de todas as amostras. $\mathrm{Na}$ análise comparativa, foram investigadas as diferentes posições radiais, os resultados foram avaliados por meio de análise de variância para medidas repetidas; devido à distribuição dos dados não ser normal, aplicou-se estatística não paramétrica (Friedman Repeated
Measures Analysis of Variance on Ranks), sendo os valores expressos em mediana e p25-p75. Quando uma diferença significante foi observada, aplicou-se o teste de Tukey para identificar o par de resultados determinantes das diferenças. Também foi realizada análise de correlação de Pearson para estudar as relações entre as características anatômicas e a densidade básica.

\section{Resultados e Discussão}

Os dados quantitativos do lenho de Pittosporum undulatum são apresentados na tabela 2 .

Caracteres macroscópicos - Cerne e alburno indistintos; cor bege claro (Munsell 1957), com brilho moderado, gosto e cheiro imperceptíveis, moderadamente dura ao corte, grã direita, textura fina, camadas de crescimento distintas. Destaca-se que apesar da espécie ser popularmente conhecida como pauincenso, em nossa análise sua madeira não apresentou cheiro, o que pode parecer um contra senso, no entanto segundo a literatura o cheiro da planta exala de suas folhas e frutos (Lago et al. 2006).

Descrição macroscópica - Parênquima axial invisível mesmo sob lente de 10x; raios visíveis a olho nu, finos a médios, muito poucos; vasos visíveis apenas sob lente de $10 \times$, muito pequenos a pequenos, pouco numerosos a numerosos, porosidade difusa uniforme, em arranjo radial, sem obstrução, camada de crescimento distinta (figura 3); raios baixos, visíveis no plano tangencial apenas sob lente de $10 \times$, não estratificados, pouco contrastados no plano radial.

Tabela 2. Análise descritiva das características anatômicas em Pittosporum undulatum.

Table 2. Descriptive analysis of anatomical features in Pittosporum undulatum.

\begin{tabular}{|c|c|c|c|c|c|c|}
\hline Características anatômicas e Densidade básica & Média & Desvio padrão & Mediana & $(\mathrm{p} 25-\mathrm{p} 75)$ & Valor mínimo & Valor máximo \\
\hline Comprimento dos elementos de vaso $(\mu \mathrm{m})$ & 768,6 & 156,5 & 767,7 & $658,2-878,8$ & 407,8 & 1242,6 \\
\hline Diâmetro dos vasos $(\mu \mathrm{m})$ & 44,9 & 12,0 & 43,5 & $35,6-53,4$ & 17,8 & 81,2 \\
\hline Frequência dos vasos $\left(\mathrm{n}^{\circ} \mathrm{mm}^{-2}\right)$ & 59,0 & 14,7 & 56,0 & $49,0-67,5$ & 29,0 & 105,0 \\
\hline Pontoações intervasculares $(\mu \mathrm{m})$ & 5,9 & 0,8 & 5,8 & $5,3-6,5$ & 4,1 & 8,8 \\
\hline Pontoações raiosvasculares $(\mu \mathrm{m})$ & 6,2 & 0,8 & 6,1 & $5,6-6,9$ & 4,6 & 8,2 \\
\hline Altura dos raios $(\mu \mathrm{m})$ & 374,9 & 120,8 & 380,8 & $294,6-458,1$ & 118,9 & 744,1 \\
\hline Largura dos raios $(\mu \mathrm{m})$ & 58,3 & 15,2 & 61,4 & $47,5-68,9$ & 17,9 & 98,5 \\
\hline Frequência dos raios $\left(\mathrm{n}^{\circ} \mathrm{mm}^{-1}\right)$ & 4,1 & 1,1 & 4,0 & $3,0-5,0$ & 1,0 & 9,0 \\
\hline Comprimento das fibras $(\mu \mathrm{m})$ & 980,6 & 147,8 & 975,2 & $888,6-1085,5$ & 497,3 & 1449,6 \\
\hline Diâmetro das fibras $(\mu \mathrm{m})$ & 23,0 & 2,9 & 23,0 & $21,2-25,0$ & 14,9 & 31,0 \\
\hline Lume das fibras $(\mu \mathrm{m})$ & 9,3 & 2,5 & 9,2 & $7,3-11,0$ & 4,2 & 17,4 \\
\hline Espessura de parede das fibras $(\mu \mathrm{m})$ & 6,8 & 1,0 & 2,8 & $6,1-7,6$ & 4,1 & 9,8 \\
\hline Densidade básica $\left(\mathrm{g} \mathrm{cm}^{-3}\right)$ & 0,60 & 0,02 & 0,61 & $0,59-0,62$ & 0,54 & 0,63 \\
\hline
\end{tabular}

$\mathrm{p} 25=$ percentil $25 ; \mathrm{p} 75=$ percentil 75 


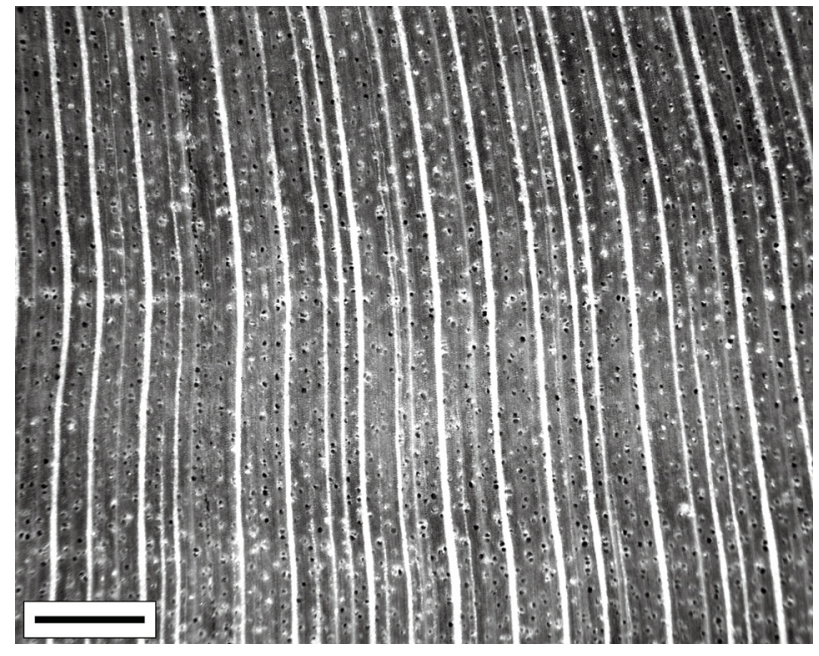

Figura 3. Superfície transversal da madeira de Pittosporum undulatum. Barra $=1 \mathrm{~mm}$.

Figure 3. Cross-sectional surface of Pittosporum undulatum wood. Scale bar $=1 \mathrm{~mm}$.

Descrição microscópica - Vasos: porosidade difusa, sendo solitários em maioria $(34,4 \%)$, geminados (23,6\%), múltiplos de três $(22,6 \%)$ e múltiplos de quatro ou mais $(19,1 \%)$, agrupados radialmente, numerosos a extremamente numerosos, com diâmetro muito pequeno a pequeno (figuras $4 \mathrm{a}-\mathrm{b}$ e tabela 2 ) de forma circular, comprimento dos elementos de vaso variando de extremamente longos a curtos com predominância de longos, com apêndices curtos e longos presentes, podendo ocorrer em apenas uma ou em ambas as extremidades (tabela 2). Os elementos de vaso possuem placas de perfuração simples oblíqua (figura 5a) e espessamento espiralado na parede observado apenas nas regiões ausentes de pontoações (figuras $5 \mathrm{a}, \mathrm{b})$, sendo as pontoações intervasculares pequenas alternas irregulares areoladas, pontoações raiovasculares semelhantes às intervasculares (figuras 5c, d). Em geral, as características qualitativas dos vasos estão de acordo com aquelas descritas por Metcalfe \& Chalk (1950) para Pittosporum, no entanto, os autores relataram a presença frequente de conteúdo amarelo em espécies do gênero, característica não observada neste estudo. Carlquist (1985) menciona a presença de traqueídes vasicêntricas em espécies de Pittosporaceae, incluindo P. undulatum, no entanto, não foram observadas no presente estudo.

Camada de crescimento: distinta, podendo ocorrer achatamento e espessamento das fibras, com presença mais distinta próxima da medula (figura 4a); em alguns indivíduos observou-se na região intermediária, camada de crescimento com leve espessamento de fibras, notar diferença entre a espessura da parede nas figuras a' e a"; a camada também é distinta pelo agrupamento dos vasos (figura $4 \mathrm{~b}$ ); na região da casca
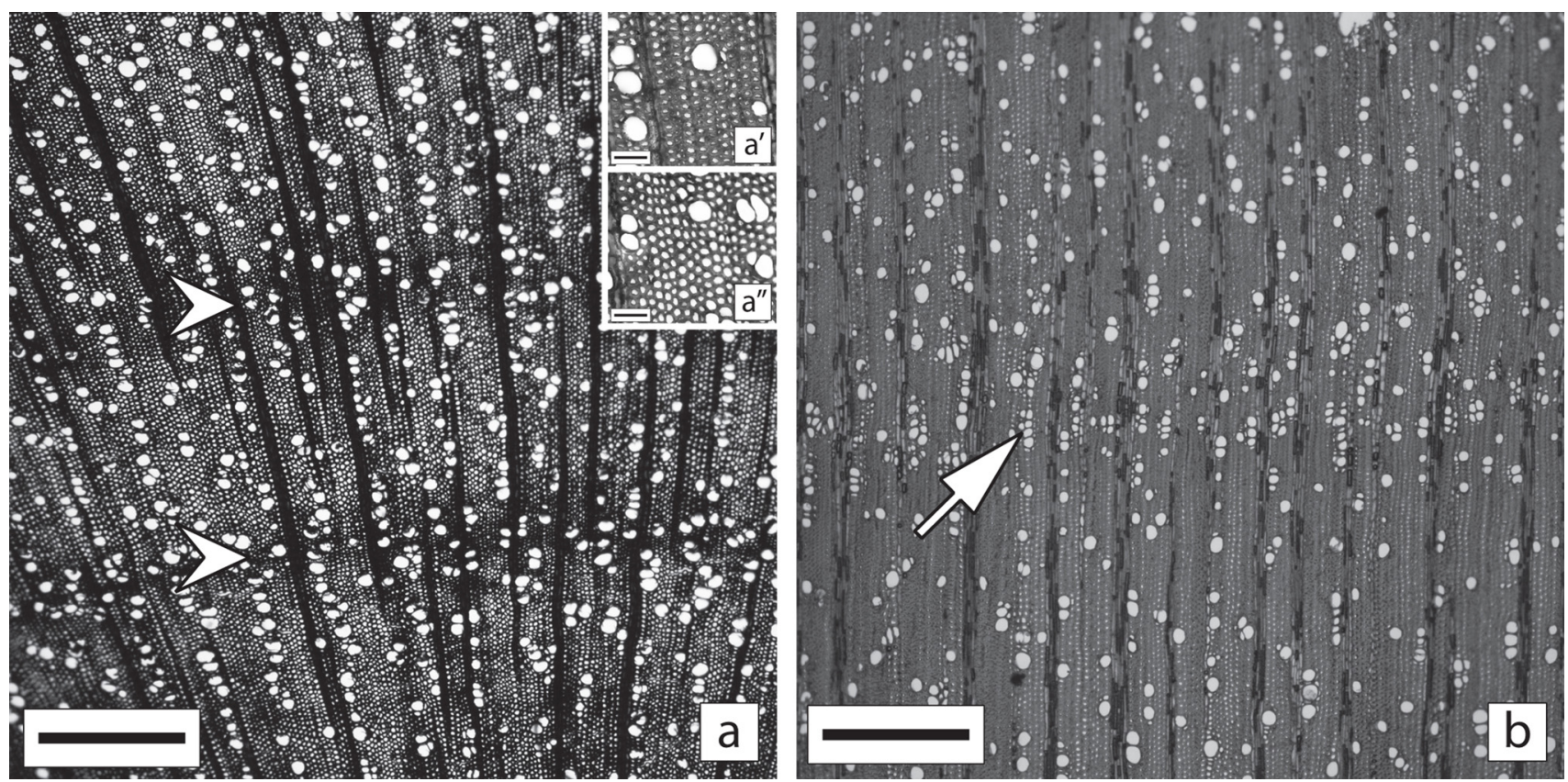

Figura 4. Secções transversais. a. Região próxima da medula, marcação das camadas de crescimento (cabeça de seta). b. Região intermediária, faixa de crescimento com vasos formando cachos (seta). Barra $=500 \mu \mathrm{m}$.

Figure 4. Transverse sections. a. Pith region, highlight the growth layers (arrowhead). b. Intermediate region, growth layer with vessels in clusters (arrow). Scale bars $=500 \mu \mathrm{m}$. 

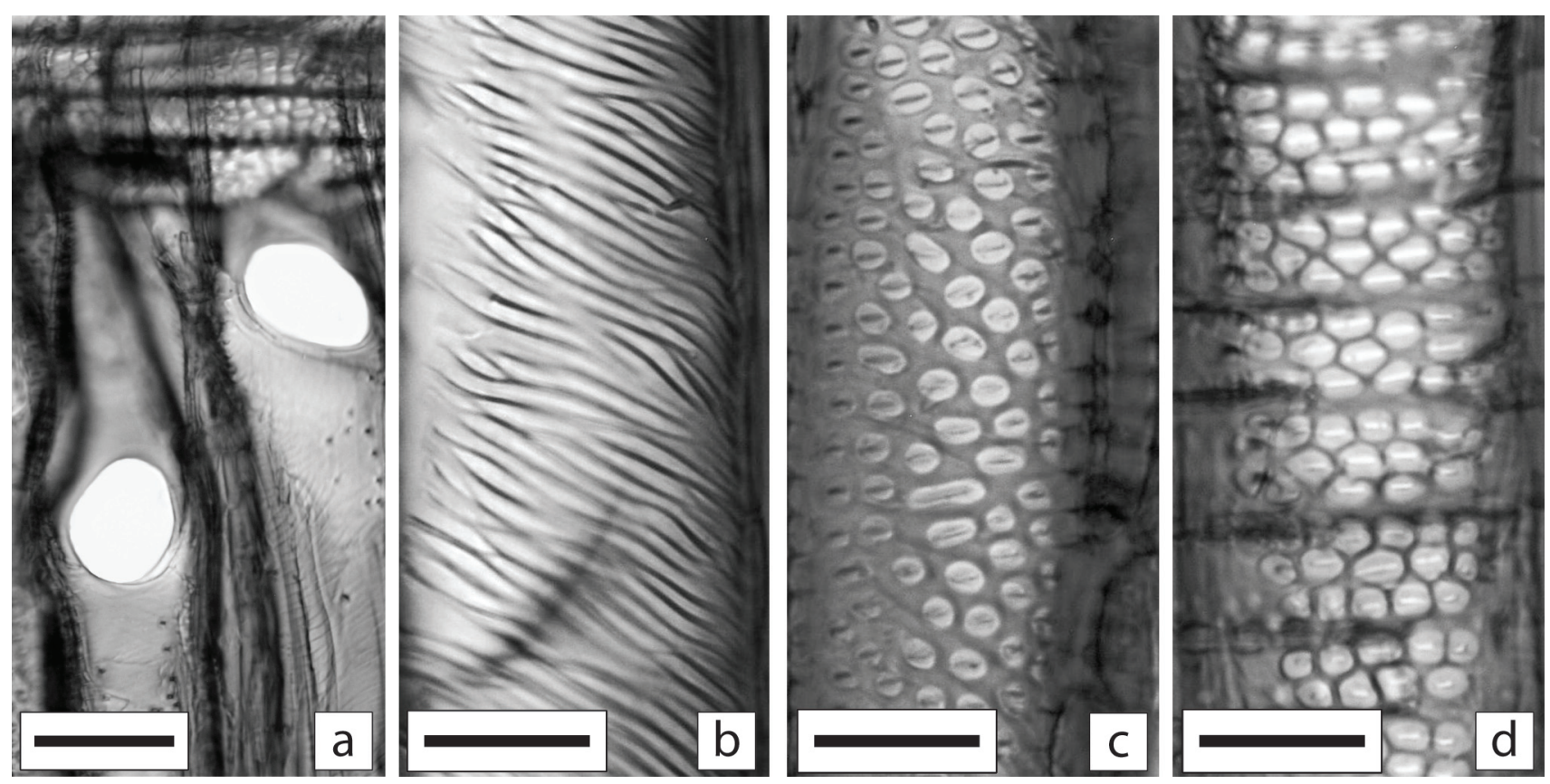

Figura 5. Secções longitudinais. a. Secção radial evidenciando placas de perfuração simples. b. Destaque para o estriamento espiral em elemento de vaso. c. Pontoações intervasculares alternas. d. Pontoações raiovasculares alternas. Barras $=50 \mu \mathrm{m}$ (a); $25 \mu \mathrm{m}$ (b, c, d).

Figure 5. Longitudinal sections. a. Radial section showing simple perforation plate. b. Spiral striations in vessel element. c. Intervessel pits alternate. d. Vessel-ray pits alternate. Scale bars $=50 \mu \mathrm{m}(\mathrm{a}) ; 25 \mu \mathrm{m}(\mathrm{b}, \mathrm{c}, \mathrm{d})$.

a camada de crescimento foi menos notada, com ocorrência de agrupamento de vasos.

Parênquima: paratraqueal escasso. O mesmo encontrado por Watson \& Dallwitz (1992) para a espécie.

Raios: não estratificados, em sua maioria multisseriados estreitos, extremamente baixos e pouco frequentes (tabela 2) podendo ser encontrado conteúdo cristalífero e oleoso, indicado devido à reação ao Sudan IV; alguns raios unisseriados também são encontrados, em geral próximos à região da medula; os raios são heterogêneos, contrastados, com células procumbentes no corpo e células quadradas e/ou eretas nas extremidades. As características dos raios estão de acordo com Metcalfe \& Chalk (1950).

Fibras: libriformes muito curtas, estreitas, septadas (figura 6a), com paredes espessas e pontoações simples, podendo ser encontradas algumas com crescimento intrusivo. Metcalfe \& Chalk (1950) e Watson \& Dallwitz (1992) reportam características semelhantes para as fibras, com exceção do crescimento intrusivo.

Cristais: presentes, encontrados em maior número nas células marginais dos raios, poucos em células procumbentes do corpo do raio (figura 6b) e raramente nas fibras (figura 6a), podendo estar nas células parenquimáticas da medula. Entre os tipos de cristais encontrados estão drusas, cristais prismáticos ou romboédricos e aglomerados de cristais de diferentes formas e tamanhos.

Variação radial das características anatômicas e densidade básica - Na tabela 3 está resumida a variação radial das características anatômicas de Pittosporum undulatum. Com exceção do diâmetro das fibras, as demais características anatômicas e a densidade básica apresentaram variação na direção da casca. Para os vasos, ocorreu aumento no diâmetro no sentido medula-casca (figuras 7a-c). Zanon et al. (2008) em Croton floribundus e Fan et al. (2009) em quatro Fagaceae também observaram aumento no diâmetro dos vasos no mesmo sentido, os últimos autores sugerem que estas variações refletem o processo de maturação do câmbio. Tsuchiya \& Furukawa (2009) mencionam que o diâmetro dos vasos pode ser empregado como um indicativo para segregar o lenho juvenil do adulto. A frequência dos vasos diminuiu em direção à casca (figuras 7a-c), o mesmo resultado encontrado por Dünisch et al. (2004) em Ilex paraguariensis. Enquanto que Silva et al. (2009) em Caesalpinia pyramidalis encontraram aumento na porcentagem dos vasos em direção da casca.

Embora diversos autores tenham destacado aumento no comprimento dos elementos de vaso no sentido medula-casca, como Dünisch et al. (2004), 

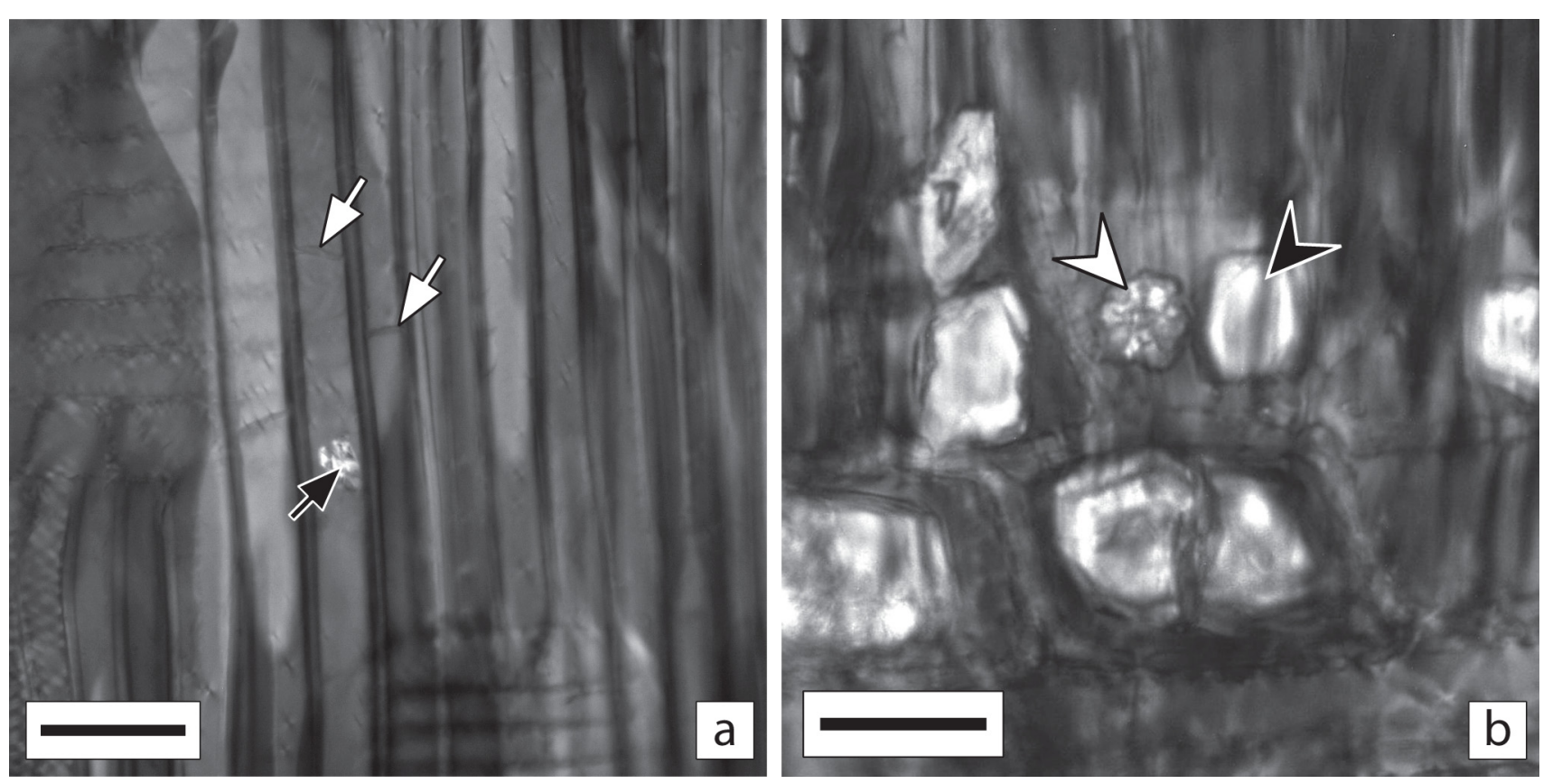

Figura 6. Secções radiais. a. Aglomerado de cristais no lume de uma fibra (seta preta); fibras septadas (setas brancas). b. Cristal prismático (cabeça de seta preta), drusa (cabeça de seta branca) em células do raio. Barras $=50 \mu \mathrm{m}$ (b); $25 \mu \mathrm{m}$ (a).

Figure 6. Radial sections. a. Cluster of crystals in the fiber lumen (black arrow); septate fibers (white arrows). b. Prismatic crystal (black arrowhead), Druse (white arrowhead) in ray cells. Scale bars $=50 \mu \mathrm{m}(\mathrm{a}) ; 25 \mu \mathrm{m}$ (b).

Zanon et al. (2008), Testoni et al. (2009) para Plathymenia reticulata e Longui et al. (2009) para Luehea divaricata, este padrão não foi observado em $P$. undulatum, que apresentou oscilação dos valores entre as posições.

O diâmetro das pontoações intervasculares variou entre as posições, já as pontoações raiovasculares mostraram aumento em direção da casca.

O agrupamento de vasos apresentou variação entre as três posições radiais estudadas, sendo que a proporção de vasos solitários diminuiu em direção da casca, enquanto que os vasos múltiplos de três apresentaram decréscimo da medula para a posição intermediária e subsequente aumento para a posição casca (figura 8).

Os índices de vulnerabilidade, mesomorfia e agrupamento de vasos aumentaram da medula para a casca (tabela 3).

Em P.undulatum houve aumento na altura, largura e frequência dos raios no sentido medula-casca (figuras 7d-i). Para a frequência, o mesmo resultado foi descrito por Zanon et al. (2008), já Urbinati et al. (2003) em Terminalia ivorensis observaram diminuição no mesmo sentido, de acordo com estes autores a diminuição na frequência dos raios próximo à casca pode ser explicada devido a diminuição das iniciais radiais e aumento das iniciais fusiformes.
O comprimento e a espessura da parede das fibras aumentaram em direção da casca, enquanto que o lume diminuiu. Já o diâmetro das fibras não apresentou variação significativa entre as posições radiais. Aumento no comprimento das fibras da medula para a casca, também foi relatado por Testoni et al. (2009), Andrade et al. (2009) para Gallesia integrifolia, Garcia et al. (2009) para Cariniana legalis, outros como Lima et al. (2008) em Cupania vernalis, Teixeira (2008) em Anadenanthera peregrina e Suckow et al. (2009) para Anadenanthera colubrina, além de aumento no comprimento, também descreveram aumento da espessura da parede das fibras e diminuição no diâmetro e lume da medula para a casca; enquanto Zanon et al. (2008) não observaram variações significativas.

A densidade básica da madeira aumentou significativamente da medula para a casca, o mesmo resultado foi encontrado por Teixeira (2008) para A. peregrina, Suckow et al. (2009) em A. colubrina e Longui et al. (2009) para L. divaricata. Enquanto que Garcia et al. (2009) para C. legalis notaram diminuição. Outros autores, não notaram variação radial significativa na densidade, como, Lima et al. (2008) em C. vernalis, Zanon et al. (2008) em C. floribundus, Andrade et al. (2009) em G. integrifolia e Testoni et al. (2009) em P. reticulata. 
Tabela 3. Análise de variância e teste de comparações múltiplas para a variação radial das características anatômicas em Pittosporum undulatum. Chi-quadrado = valor do teste de significância estatística, $p=$ grau de significância. Os valores são apresentados em mediana (p25-p75). Na mesma linha, valores seguidos de letras distintas diferem estatisticamente em $(\mathrm{p}<0,05)$ pelo teste de Tukey.

Table 3. Analysis of variance and multiple comparison test for the radial variation of anatomical features in Pittosporum undulatum. Chi-quadrado $=$ statistical significance test, $p=$ significance levels. Anatomical features are expressed as median (p25-p75). In the same line, values followed by distinct letters differ statistically at $(\mathrm{p}<0.05)$ by Tukey test.

\begin{tabular}{|c|c|c|c|c|c|}
\hline \multirow[b]{2}{*}{ Características anatômicas } & \multicolumn{3}{|c|}{ Posição na árvore } & \multicolumn{2}{|c|}{$\begin{array}{l}\text { Friedman Repeated } \\
\text { Measures Analysis of } \\
\text { Variance on Rankss }\end{array}$} \\
\hline & Medula & Intermediária & Casca & Chi-quadrado & $p$ \\
\hline Comprimento dos elementos de vaso $(\mu \mathrm{m})$ & $\begin{array}{c}754,5 \mathbf{a}, \mathbf{b} \\
(662,6-857,8)\end{array}$ & $\begin{array}{c}791,4 \mathbf{a} \\
(697,8-906,4)\end{array}$ & $\begin{array}{c}767,7 \mathbf{b} \\
(598,4-875,2)\end{array}$ & 6,727 & $(0,035)$ \\
\hline Diâmetro dos vasos $(\mu \mathrm{m})$ & $\begin{array}{c}38,8 \mathbf{c} \\
(30,9-44,5)\end{array}$ & $\begin{array}{c}45,5 \mathbf{b} \\
(37,6-53,4)\end{array}$ & $\begin{array}{c}51,4 \mathbf{a} \\
(42,5-58,4)\end{array}$ & 39,843 & $(0,001)$ \\
\hline Frequência dos vasos $\left(\mathrm{n}^{\mathrm{o}} \mathrm{mm}^{-2}\right)$ & $\begin{array}{c}68,5 \mathbf{a} \\
(55,0-82,5)\end{array}$ & $\begin{array}{c}53,0 \mathbf{b} \\
(44,5-59,5)\end{array}$ & $\begin{array}{c}54,5 \mathbf{b} \\
(49,0-59,5)\end{array}$ & 44,086 & $(0,001)$ \\
\hline Pontoações intervasculares $(\mu \mathrm{m})$ & $\begin{array}{c}5,8 \mathbf{a}, \mathbf{b} \\
(5,2-6,4)\end{array}$ & $\begin{array}{c}5,6 \mathbf{b} \\
(5,2-6,0)\end{array}$ & $\begin{array}{c}6,3 \mathbf{a} \\
(5,6-6,9)\end{array}$ & 8,541 & $(0,014)$ \\
\hline Pontoações raiovasculares $(\mu \mathrm{m})$ & $\begin{array}{c}5,9 \mathbf{b} \\
(5,4-6,2)\end{array}$ & $\begin{array}{c}6,3 \mathbf{a} \\
(5,7-6,9)\end{array}$ & $\begin{array}{c}6,4 \mathbf{a} \\
(5,8-7,2)\end{array}$ & 18,430 & $(0,001)$ \\
\hline Índice de vulnerabilidade & $\begin{array}{c}0,5 \mathbf{b} \\
(0,4-0,7)\end{array}$ & $\begin{array}{c}0,8 \mathbf{a} \\
(0,6-1,1)\end{array}$ & $\begin{array}{c}0,8 \mathbf{a} \\
(0,6-1,0)\end{array}$ & 54,080 & $(0,001)$ \\
\hline Índice de mesomorfia & $\begin{array}{c}434,9 \mathbf{b} \\
(349,7-532,4)\end{array}$ & $\begin{array}{c}670,8 \mathbf{a} \\
(534,2-846,6)\end{array}$ & $\begin{array}{c}627,4 \mathbf{a} \\
(491,8-811,5)\end{array}$ & 51,440 & $(0,001)$ \\
\hline Índice de agrupamento de vasos & $\begin{array}{c}1,68 \mathbf{b} \\
(1,5-1,8)\end{array}$ & $\begin{array}{c}1,71 \mathbf{a}, \mathbf{b} \\
(1,5-2,0)\end{array}$ & $\begin{array}{c}1,77 \mathbf{a} \\
(1,5-1,9)\end{array}$ & 7,855 & $(0,020)$ \\
\hline Altura dos raios $(\mu \mathrm{m})$ & $\begin{array}{c}269,3 \mathbf{b} \\
(210,0-363,7)\end{array}$ & $\begin{array}{c}415,6 \mathbf{a} \\
(330,3-487,7)\end{array}$ & $\begin{array}{c}415,6 \mathbf{a} \\
(336,4-490,1)\end{array}$ & 62,242 & $(0,001)$ \\
\hline Largura dos raios $(\mu \mathrm{m})$ & $\begin{array}{c}41,5 \mathbf{b} \\
(39,6-55,6)\end{array}$ & $\begin{array}{c}68,9 \mathbf{a} \\
(59,3-73,9)\end{array}$ & $\begin{array}{c}64,0 \mathbf{a} \\
(59,1-68,9)\end{array}$ & 112,046 & $(0,001)$ \\
\hline Frequência dos raios $\left(\mathrm{n}^{\circ} \mathrm{mm}^{-1}\right)$ & $\begin{array}{c}4 \mathbf{b} \\
(3-4)\end{array}$ & $\begin{array}{c}4 \mathbf{a} \\
(3,5-5)\end{array}$ & $\begin{array}{c}4 \mathbf{a} \\
(4-5)\end{array}$ & 20,025 & $(0,001)$ \\
\hline Comprimento das fibras $(\mu \mathrm{m})$ & $\begin{array}{c}920,3 \mathbf{~ b} \\
(842,3-995,5)\end{array}$ & $\begin{array}{c}1035,2 \mathbf{a} \\
(925,3-1136,4)\end{array}$ & $\begin{array}{c}988,0 \mathbf{a} \\
(895,2-1108,4)\end{array}$ & 20,224 & $(0,001)$ \\
\hline Diâmetro das fibras $(\mu \mathrm{m})$ & $\begin{array}{c}23,2 \mathbf{a} \\
(20,6-25,1)\end{array}$ & $\begin{array}{c}23,4 \mathbf{a} \\
(21,4-25,4)\end{array}$ & $\begin{array}{c}22,7 \mathbf{a} \\
(21,2-24,5)\end{array}$ & 3,052 & $(0,217)$ \\
\hline Lume das fibras $(\mu \mathrm{m})$ & $\begin{array}{c}10,2 \mathbf{a} \\
(8,4-12,3)\end{array}$ & $\begin{array}{c}9,1 \mathbf{a}, \mathbf{b} \\
(7,2-10,6)\end{array}$ & $\begin{array}{c}8,0 \mathbf{b} \\
(6,6-9,7)\end{array}$ & 16,763 & $(0,001)$ \\
\hline Espessura de parede das fibras $(\mu \mathrm{m})$ & $\begin{array}{c}6,2 \mathbf{b} \\
(5,5-6,9)\end{array}$ & $\begin{array}{c}7,1 \mathbf{a} \\
(6,5-7,6)\end{array}$ & $\begin{array}{c}7,1 \mathbf{a} \\
(6,4-8,0)\end{array}$ & 41,835 & $(0,001)$ \\
\hline
\end{tabular}

Segundo Bhat et al. (2001) a marcação entre madeira juvenil e adulta tem sido realizada com base na variação radial das características anatômicas. No presente estudo, notou-se para várias características anatômicas, como o diâmetro dos vasos, altura e largura dos raios e comprimento das fibras valores diferentes entre a posição medula e as duas posições mais externas (intermediária e casca), o que pode indicar o término do lenho juvenil e o início do lenho adulto. Considerando o DAP médio de $16 \mathrm{~cm}$ das árvores aqui estudadas e que as amostras entre as três posições radiais foram retiradas com dimensões próximas, pode-se inferir que o lenho juvenil deve corresponder a cerca de $5,3 \mathrm{~cm}$, ou seja a uma terça parte do diâmetro total das árvores estudadas.

Correlação entre densidade básica e anatomia da madeira - Detectou-se correlação positiva significante entre a densidade básica e a espessura da parede das fibras (figura 9, tabela 4). Este resultado foi semelhante aos citados por Fujiwara et al. (1991) em madeiras japonesas, Denne \& Hale (1999) em Nothofagus nervosa, Quilhó et al. 2006 em híbridos de Eucalyptus grandis e E. urophylla, Ishiguri et al. (2009) em Paraserianthes falcataria, Longui (2009) em Dipteryx spp. e Longui et al. (2009) em L. divaricata, as duas últimas espécies nativas. Sem 
dúvida, as demais características anatômicas podem influenciar na densidade da madeira, no entanto de acordo Fujiwara et al. (1991), correlações entre as características das fibras e as propriedades são esperadas, uma vez que estas células constituem a maior parte da madeira, portanto têm grande influência nas suas propriedades, especialmente na densidade. Dessa forma o aumento na espessura da parede das fibras representa um aumento na massa e consequentemente na densidade básica da madeira. O que é notada pela variação radial da característica anatômica e da propriedade física.
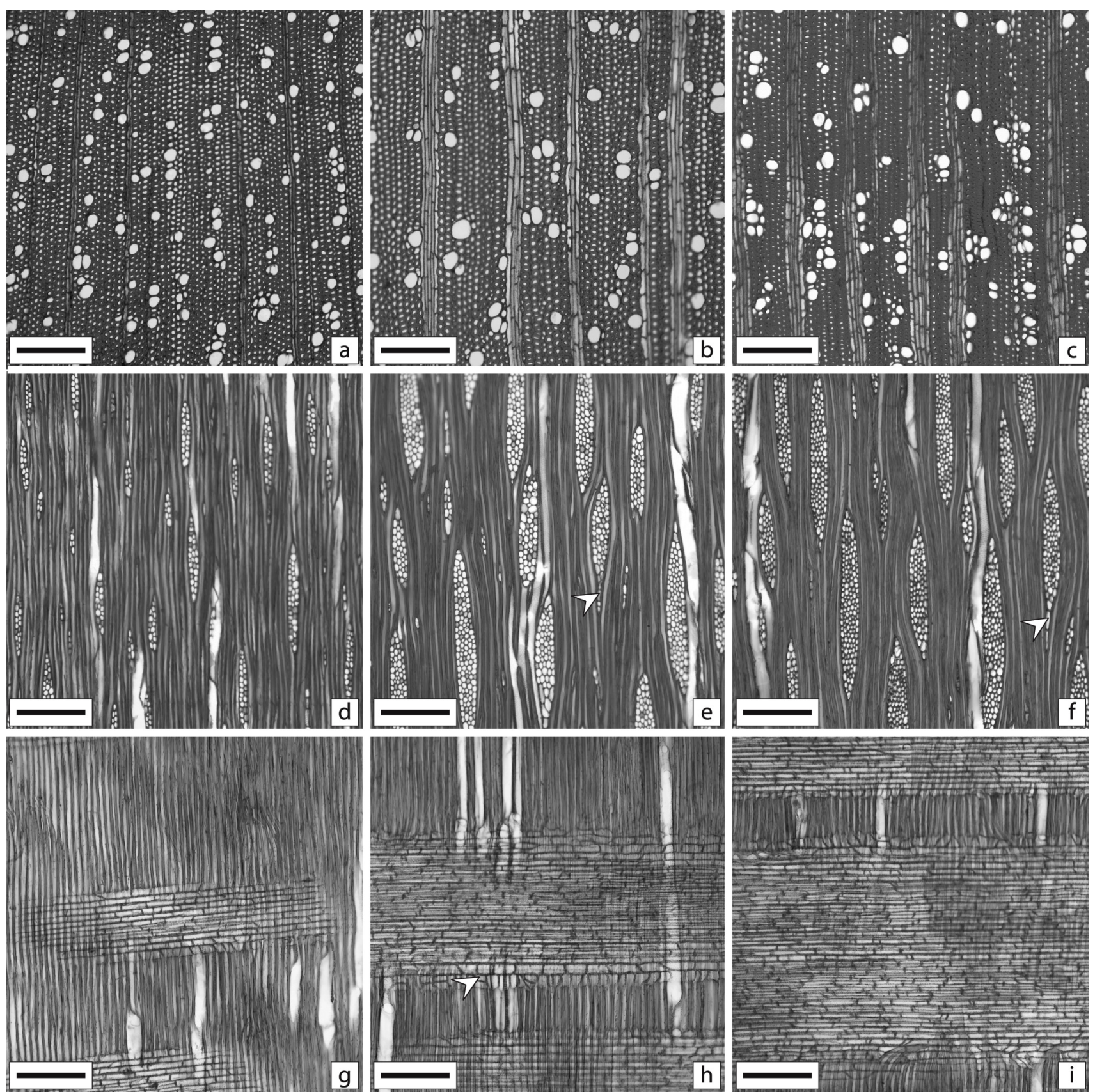

Figuras 7. Variação radial. a-c. secções transversais. a. medula. b. intermediária. c. casca. d-f. Secções tangenciais. d. medula. e. intermediária. f. casca. g-i. Secções radiais. g. medula. h. intermediária. i. casca. Notar a composição celular dos raios nas figuras e, f, h: corpo dos raios com células procubentes e células quadradas e/ou eretas nas extremidades (cabeça de seta). Barras $=200 \mu \mathrm{m}$.

Figure 7. Radial variation. a-c. Transverse sections. a. pith. b. intermediate. c. bark. d-f. Tangential sections. d. pith. e. intermediate. f. bark. g-i. Radial sections. g. pith. h. intermediate. i. bark. Note the cellular composition of the rays in figures e, f, h: body ray cells procumbent and upright and/or square marginal cells (arrowhead). Scale bars $=200 \mu \mathrm{m}$. 


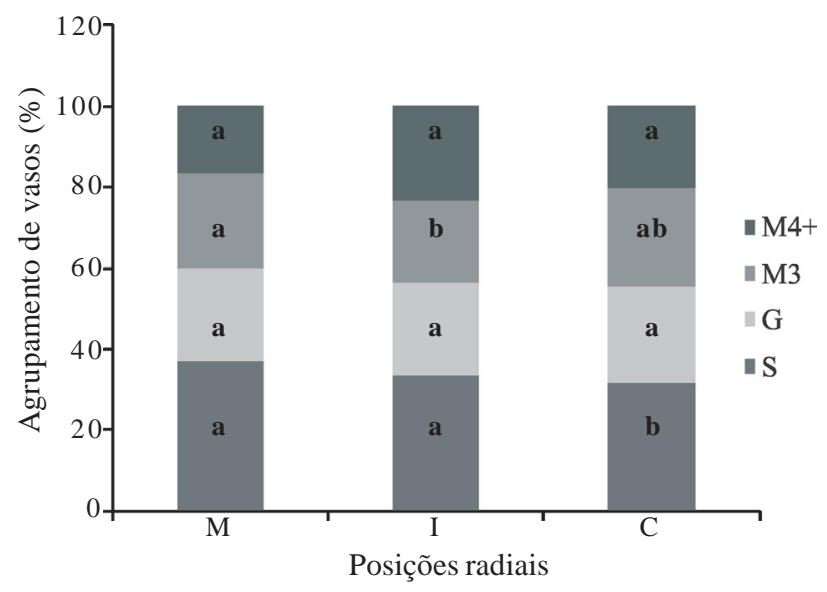

Figura 8. Variação radial no agrupamento de vasos (\%) em Pittosporum undulatum. $\mathrm{S}=$ solitários; $\mathrm{G}=$ geminados; M3 = múltiplos de 3; M4+ = múltiplos de 4 ou mais. Posições radiais: $\mathrm{M}=$ medula; $\mathrm{I}=$ intermediária e $\mathrm{C}=$ casca.

Figure 8. Radial variation on vessel groupings (\%) in Pittosporum undulatum. $\mathrm{S}=$ solitary; $\mathrm{G}=$ multiples of $2 ; \mathrm{M} 3=$ multiples of 3; M4+ = multiples of 4 or more. Radial positions: $\mathrm{M}=$ pith; $\mathrm{I}=$ intermediate and $\mathrm{C}=$ bark.

Análise ecológica do lenho - A relação entre as características anatômicas do lenho e os fatores ambientais é reconhecida há muito tempo, em especial as alterações no xilema decorrentes da disponibilidade hídrica. Carlquist (1985) em estudo com a flora do sul da Califórnia e áreas similares, encontrou em diversas espécies maior presença de traqueídes vasicêntricas no lenho de plantas em áreas com baixa disponibilidade de água, incluindo $P$. undulatum. Neste estudo, a análise tanto do material macerado quanto das secções não revelou a presença destas células, mesmo existindo no PEAL três meses com déficit hídrico, abril, junho e agosto, sendo este último mais representativo, com $3,5 \mathrm{~mm}$ (figura 1), além de um período seco que se estende de abril a agosto, especula-se que mesmo com estas condições, ainda havia água disponível no solo, ao menos em quantidade necessária para não expor as plantas de $P$. undulatum a uma situação mais intensa de estresse hídrico, o que segundo Carlquist (1985), poderia ocasionar o desenvolvimento de traqueídes vasicêntricas.

Contudo analisando os índices de vulnerabilidade (IV) e mesomorfia (IM) em P. undulatum, observa-se que o valor do IV abaixo de um está dentro do esperado para plantas que investem na segurança sob condições de estresse hídrico, portanto adaptadas a condições de menor disponibilidade de água. Já o índice de mesomorfia é superior a 200, o que indica adaptação a condições mésicas (Carlquist 1977, Dickison 2000). Goulart \& Marcati (2008) em Lippia salviifolia em área de Cerrado encontraram valores de IV entre 0,6 e 1 e IM entre 158-257, concluindo que estes indicavam que a espécie está adaptada às condições xéricas. É interessante destacar que em comparação com indivíduos de Piptadenia gonoacantha estudada por

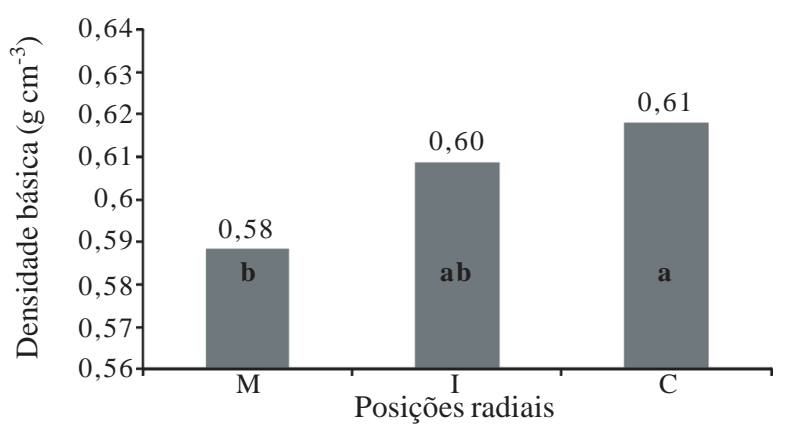

Figura 9. Variação radial da densidade básica $\left(\mathrm{g} \mathrm{cm}^{-3}\right)$ em função da posição radial em Pittosporum undulatum. $\mathrm{M}=$ medula; $\mathrm{I}=$ intermediária; $\mathrm{C}=$ casca.

Figure 9. Radial variation of basic density $\left(\mathrm{g} \mathrm{cm}^{-3}\right)$ as a function of radial positions in Pittosporum undulatum. $\mathrm{M}=$ pith; $\mathrm{I}=$ intermediate $\mathrm{C}=$ bark.

Tabela 4. Coeficiente de correlação de Pearson $(r)$ e grau de significância ( $p$ ) entre a densidade básica e as características anatômicas em Pittosporum undulatum. DV = diâmetro dos vasos; $\mathrm{CV}=$ comprimentos dos elementos de vaso; $\mathrm{FV}=$ frequência de vasos; $\mathrm{AR}=$ altura dos raios; $\mathrm{LR}=$ largura dos raios; $\mathrm{FR}=$ frequência dos raios; $\mathrm{CF}=$ comprimento das fibras; $\mathrm{DF}=$ diâmetro das fibras; $\mathrm{LF}=$ lume das fibras; $\mathrm{PF}=$ espessura da parede das fibras.

Table 4. Pearson's coefficient of correlation $(r)$ and significance level $(p)$ between basic density and anatomical features in Pittosporum undulatum. $\mathrm{DV}=$ vessel diameter, $\mathrm{CV}=$ vessel element length; $\mathrm{VF}=$ vessel frequency, $\mathrm{AR}=$ rays height, $\mathrm{LR}=$ ray width, $\mathrm{FR}=$ ray frequency; $\mathrm{CF}=$ fiber length, $\mathrm{DF}=$ fiber diameter; $\mathrm{LF}=$ fiber lumen diameter, $\mathrm{PF}=$ fiber wall thickness.

\begin{tabular}{crrrrrrrrrr}
\hline & \multicolumn{1}{c}{ Características anatômicas } \\
\cline { 2 - 10 } Densidade básica & CV & DV & FV & AR & LR & FR & CF & DF & LF & PF \\
\hline$r$ & $-0,119$ & 0,210 & $-0,426$ & 0,442 & 0,482 & 0,255 & 0,349 & 0,236 & $-0,421$ & $\mathbf{0 , 5 7 6}$ \\
$p$ & 0,712 & 0,513 & 0,168 & 0,150 & 0,113 & 0,424 & 0,266 & 0,460 & 0,173 & $\mathbf{0 , 0 5 0 *}$ \\
\hline
\end{tabular}

* Significante a $\mathrm{p} \geq 0,05$ indicados em negrito.

* Significant $p$ values with $\mathrm{p} \geq 0.05$ have been indicated with bold letters. 
Longui et al. (2009), no Parque Estadual Cantareira, em local próximo ao PEAL, e portanto com condições climáticas semelhantes, $P$. undulatum possui IV de 0,7 (média entre as três posições radiais) valor bem abaixo do que o mencionado para $P$. gonoacantha $(14,6)$.

Tal resultado pode indicar para $P$. undulatum um maior investimento na segurança do xilema do que na eficiência, ou que nesta espécie os fatores genéticos parecem influenciar mais do que os ambientais na estrutura do lenho. Os resultados de Van der Graaff \& Baas (1974) parecem reforçar esta idéia, pois os autores em estudo com $P$. undulatum não encontraram correlação entre a altitude e as características anatômicas, e mencionaram que estas apresentaram pequena variação entre indivíduos que ocorriam ao nível do mar e a $2.667 \mathrm{~m}$ de altitude.

A frequência dos vasos solitários diminuiu significativamente da medula para a casca (figura 8). Carlquist \& Hoekman (1985) e Bass \& Schweingruber (1987) reportam entre outras características, que o agrupamento em vasos múltiplos é uma das estratégias que confere maior segurança ao lenho. Nesse contexto pode se especular que conforme o tronco das árvores de P. undulatum cresce em diâmetro, as mesmas, desenvolvem maior segurança no transporte de água. Roque et al. (2007) e Roque \& Tomazello Filho (2009) em Gmelina arborea em diferentes condições de clima e de manejo na Costa Rica, não observaram variação radial na porcentagem de vasos múltiplos, contudo encontraram maior frequência de vasos geminados e múltiplos de 3 a 4 em ambiente mais seco.

Comparado com espécies nativas, $P$. undulatum apresenta vasos de menores diâmetros, o que poderia indicar menor eficiência no transporte de água através da planta, no entanto a frequência de vasos é maior, o que segundo McCulloh \& Sperry (2005) também é uma alternativa para aumentar a eficiência hidráulica. Segundo Carlquist (1977 e 2001) a ocorrência de menor frequência de vasos e elementos de vaso mais longos e com maior diâmetro é mais comum em espécies de florestas tropicais.

Barros et al. (2006) avaliando tendências ecológicas na madeira de árvores em remanescente de Mata Atlântica no Rio de Janeiro, local com pluviosidade média anual de $2.260 \mathrm{~mm}$ e $24,5^{\circ} \mathrm{C}$, encontraram valores de 1,0 a 2,3 para o índice de agrupamento de vasos (IAV). O valor do IAV em $P$. undulatum aumentou significativamente da região próxima à medula para a casca, e em média $(1,72)$, esteve dentro do intervalo descrito por Barros et al.
(2006), contudo os autores reportaram, para as espécies por eles estudadas, menor frequência de vasos, com maior diâmetro e placa de perfuração simples, o que caracteriza adaptação a ambientes com boa disponibilidade de água, sem estresse hídrico, sendo que estas características propiciam o transporte de grandes volumes de água. Com relação a este aspecto, $P$. undulatum, dentre estas características coincide apenas na presença de placas de perfuração simples, uma vez que apresenta vasos de diâmetro muito pequeno (menor que $50 \mathrm{~mm}$ ) e muito frequentes $\left(59\right.$ vasos $\mathrm{mm}^{-2}$ ). Outro resultado interessante a ser destacado é a ocorrência de agrupamento de vasos demarcando a camada de crescimento, o que também pode representar uma estratégia de segurança no período anterior aos meses com déficit hídrico.

Outro aspecto, que parece associar o lenho de $P$. undulatum a locais mais secos é a grande concentração de cristais encontrada nas três posições radiais. Barajas-Morales (1985), em estudo com árvores de florestas seca e úmida e Lima et al. (2009) em Enterolobium contortisiliquum ocorrendo na caatinga e em floresta, encontraram maior quantidade de cristais em ambientes mais secos. De acordo com Nakata (2003), a formação de cristais de oxalato de cálcio nas plantas parece estar relacionada à regulação de cálcio, proteção contra herbivoria e desintoxicação de metais. Cristais na madeira ocorrem especialmente nas células de parênquima axial ou radial, a sua presença e tipo têm importância taxonômica, como mencionado por Jansen et al. (2002) em diferentes espécies de Rubiaceae.

Quanto à formação das camadas de crescimento, Worbes (1995) menciona que uma estação seca anual, com dois a três meses de precipitação menor que $60 \mathrm{~mm}$ induz a formação de camadas de crescimento anuais nas árvores tropicais. De acordo com o diagrama climático (figura 1), observa-se para o PEAL, uma estação seca de abril a agosto, com precipitações inferiores a $60 \mathrm{~mm}$ nos meses de junho a agosto (respectivamente, $37,7 \mathrm{~mm}$; $47 \mathrm{~mm}$ e $31,7 \mathrm{~mm}$ ) assim, sugere-se que as camadas de crescimento observadas em $P$. undulatum sejam formadas em decorrência destas condições climáticas.

A variação na densidade da madeira também pode ser discutida em um contexto ecológico, de acordo com Wiemann \& Williamson (1989) o aumento radial da densidade pode estar relacionado ao grupo sucessional, uma vez que espécies pioneiras crescem rapidamente nos primeiros anos de vida provavelmente 
devido à competição com outras árvores, o que implica em madeira mais leve; no entanto quando a árvore desenvolve a altura necessária para absorver luz satisfatoriamente, parece que existe um ajuste gradual que permite estabilizar estruturalmente a árvore propiciando um reforço mecânico para sustentação da copa. Está pode ser uma explicação para o aumento na densidade da madeira em direção da casca em P. undulatum, pois segundo Barrett \& Ash (1992), a espécie é considerada pioneira. Vários autores mencionam a relação positiva entre a densidade e outras propriedades da madeira, como as resistências à flexão e ruptura (Panshin \& De Zeeuw 1980, Hoadley 2000), assim acredita-se que o aumento da densidade contribui para o reforço mecânico conforme as árvores de $P$. undulatum crescem.

A maioria das características anatômicas está de acordo com o descrito na literatura para o gênero Pittosporum, contudo ressalta-se a presença de camadas de crescimento marcadas pelo espessamento das fibras e também pelo agrupamento dos vasos, característica não encontrada na literatura. Com exceção do diâmetro das fibras, as demais características anatômicas apresentaram variação na direção da casca, o mesmo foi notado para a densidade básica e os índices de vulnerabilidade, mesomorfia e agrupamento de vasos. Destaca-se que em geral a região próxima da medula diferiu das outras duas posições mais externas, o que parece indicar a presença de lenho juvenil nesta região.

Houve correlação positiva entre a densidade básica e a espessura da parede das fibras, sendo que esta última característica foi maior nas posições intermediária e casca, o que sugere um aumento no reforço mecânico conforme as árvores crescem em diâmetro e aumentam suas copas.

A análise ecológica do lenho indicou, para P. undulatum, maior investimento na segurança do xilema do que na eficiência com relação ao transporte de água, uma vez que o índice de vulnerabilidade menor do que um (1) está relacionado a plantas adaptadas a condições de menor disponibilidade de água. Além disso, destaca-se a ocorrência de agrupamento de vasos demarcando a camada de crescimento, o que pode contribuir com a segurança no período anterior aos meses com déficit hídrico. Associado as características dos vasos, observou-se grande quantidade de cristais, distribuídos em todas as posições radiais, o que segundo a literatura também pode ser associado a plantas sujeitas a menor disponibilidade hídrica.

\section{Literatura citada}

Andrade, I.M., Longui, E.L., Lima, I.L. \& Florsheim, S.M.B. 2009. Efeito da procedência na variação radial do comprimento de fibras e densidade básica da madeira de Gallesia integrifolia. IF Série Registros 40: 39-43.

Arzolla, F.A.R.D.P., Moura, C., Vilela, F.E.S.P., Franco, G.A.D.C., Modler, I.F., Mattos, I.F.A., Pastore, J.A., Baitello, J.B., Castro, N.I., Aguiar, O.T., Cielo Filho, R., Souza, S.C.P.M., Silva, V.S., Costa, N.O., Lima, P.F. \& Almeida, R.S. 2009. Avaliação do meio biótico In: Leonel, C. (coord.) Plano de Manejo do Parque Estadual Alberto Löfgren. Instituto Florestal - SMA, São Paulo, pp. 111-143.

Barajas-Morales, J. 1985. Wood structural differences between trees of two tropical forests in Mexico. IAWA Bulletin 6: 355-364.

Barrett, D.J. \& Ash, J.E. 1992.Growth and Carbon Partitioning in Rainforest and Eucalypt Forest Species of South Coastal New South Wales. Australian Journal of Botany 40: 13-25.

Barros, C.F., Marcon-Ferreira, M.L., Callado, C.H., Lima, H R.P., Cunha, M., Marquete, O. \& Costa C.G. 2006. Tendências ecológicas na anatomia da madeira de espécies da Comunidade arbórea da Reserva Biológica de Poço das Antas, Rio de Janeiro, Brasil. Rodriguésia 57:443-460.

Baas, P. \& Schweingruber, F.H. 1987. Ecological trends in the wood anatomy of trees, shrubs and climbers from Europe. IAWA Bulletin 8: 245-274.

Bellingham, P.J., Tanner, E.V.J. \& Healey, J.R. 2005. Hurricane disturbance accelerates invasion by the alien tree Pittosporum undulatum in Jamaican montane rain forests. Journal of Vegetation Science 16: 675-684.

Berlyn, G.P. \& Miksche, J.P. 1976. Botanical microtechnique and cytochemistry. The Iowa University Press, Iowa.

Bhat, K.M., Priya, P.B. \& Rugmini, P. 2001. Characterization of juvenile wood in teak. Wood Science Technology 34: 517-532.

Binggeli, P. \& Goodland, T. 1997. Pittosporum undulatum. Woody Plant Ecology. Summary: Good overview of general information on $P$. undulatum. Useful as a quick summary. http://members.lycos.co.uk/Woody Plant Ecology/docs/web-sp15.htm (acesso em 8.01.2010).

Blum, C.T., Posonski, M., Hoffmann, P.M. \& Borgo, M. 2004. Espécies vegetais invasoras em comunidades florestais nativas nas margens da represa do Vossoroca, APA de Guaratuba, Paraná, Brasil. http:// www.chaua.org.br/pagina/plantas-exoticas-invasorasna-represa-vossoroca (acesso em 8.01.2010).

Bubner, B. 2008. The wood cross sections of Hermann Nördlinger (1818-1897). IAWA Journal 29: 439-457.

Carlquist, S. 1977. Ecological factors in wood evolution: a floristic approach. American Journal of Botany 64: 887-896. 
Carlquist, S. 1981. Wood anatomy of Pittosporaceae. Allertonia 2: 191-246.

Carlquist, S. 1985. Vasicentric tracheids as a drought survival mechanism in the woody flora of southern California and similar regions; review of vasicentric tracheids. Aliso 11: 37-68.

Carlquist, S. \& Hoekman, D.A. 1985. Ecological wood anatomy of the woody Southern Californian flora. IAWA Bulletin 6: 319-347.

Carlquist, S. 2001. Comparative wood anatomy: systematic, ecological and evolutionary aspects of dicotyledon wood. 2 ed. Springer-Verlag, Berlin.

Coradin, V.T.R. \& Muniz, G.I.B. 1992. Normas e procedimentos em estudos de anatomia da madeira: I Angispermae, II - Gimnospermae. Série Técnica 15. IBAMA, DIRPED, LPF, Brasília.

Denne, M.P. \& Hale, M.D. 1999. Cell wall and lumen percentages in relation to wood density of Nothofagus nervosa. IAWA Journal 20: 23-26.

Dickison, W.C. 2000. Integrative plant anatomy. Academic Press, San Diego.

Dünisch, O., Reissmann, C.B. \& Oliszeski, A.V. 2004. Variability of vessel characteristics in xylem of Ilex paraguariensis (mate-tree) from south Brazil. IAWA Journal 25: 449-458.

Fan, Z.X., Cao, K.F. \& Becker, P. 2009. Axial and radial variations in xylem anatomy of angiosperm and conifer trees in Yunnan, China. IAWA Journal 30: 1-13.

Foelkel, C.E.B. 1971. Método do máximo teor de umidade aplicado à determinação da densidade básica da madeira de Eucalyptus spp. IPEF 23: 65-74.

Franco, G.A.D.C., Souza, F.M., Ivanauskas, N.M., Mattos, I.F. A., Baitello, J.B., Aguiar, O.T., Catarucci, A.F.M. \& Polisel, R.T. 2007. Importância dos remanescentes florestais de Embu (SP, Brasil) para a conservação da flora regional. Biota Neotropica 7: 145-161.

Fujiwara, S., Sameshima, K., Kuroda, K. \& Takamura, N. 1991. Anatomy and properties of Japanese hardwoods I. Variation of dimensions of ray cells and their relation to basic density. IAWA Bulletin 12: 419-424.

Garcia, M.F., Florsheim, S.M.B., Lima, I.L. \& Longui, E.L. 2009. Variação radial da densidade básica e comprimento de fibras de diferentes procedências de Carianiana legalis. IF Florestal Série Registros 40: 75-80.

Gleadow, R.M. \& Ashton, D.H. 1981. Invasion by Pittosporum undulatum of the Forests of Central Victoria. I. Invasion Patterns and Plant Morphology. Australian Journal of Botany 29: 705-720.

Goodland, T. \& Healey, J.R. 1996. The invasion of Jamaican montane rainforests by the Australian tree Pittosporum undulatum. School of Agricultural and Forest Sciences, University of Wales, Bangor.
Goodland, T. \& Healey, J.R. 1997. The effect of Pittosporum undulatum on the native vegetation of the Blue Mountains of Jamaica. Report by the Invasive Woody Plants in the Tropics Research Group. School of Agricultural and Forest Sciences, University of Wales, B angor. www.bangor.ac.uk/wafs $101 /$ iwpt / welcome.shtml (acesso em 28.01.2010).

Goulart, S.L. \& Marcati, C.R. 2008. Anatomia comparada do lenho em raiz e caule de Lippia salviifolia Cham. (Verbenaceae). Revista Brasileira de Botânica 31: 263-275.

Hoadley, B. 2000. Understanding Wood: A Craftsman's Guide to Wood Technology. 2 ed. Taunton, Newtown.

Iawa Committee. 1989. IAWA list of microscopic features for hardwood identification. IAWA Bulletin 10: 219-332.

Ishiguri, F., Hiraiwa, T., Iizuka, K., Yokota, S., Priadi, D., Sumiasri, N. \& Yoshizawa, N. 2009. Radial variation of anatomical characteristics in Paraserianthes falcataria planted in Indonesia. IAWA Journal 30: 343-352.

Jansen, S., Robbrecht, E., Beeckman, H. \& Smets, E. 2002. A survey of the systematic wood of the Rubiaceae. IAWA Journal 23: 1-67.

Johansen, D.A. 1940. Plant microtechnique. McGraw-Hill Book, New York.

Lake, J.C. \& Leishman, M.R. 2004. Invasion success of exotic plants in natural ecosystems: the role of disturbance, plant attributes and freedom from herbivores Biological Conservation 117: 215-226

Lago, J.H.G., Fávero, O.A. \& Romoff, P. 2006. Microclimatic Factors and Phenology Influences in the Chemical Composition of the Essential Oils from Pittosporum undulatum Vent. leaves. Journal of Brazilian Chemical Society 17: 1334-1338.

Lima, I.L., Florsheim, S.M.B. \& Aguiar, O.T. 2008. Variação radial da densidade celulares de Cupania vemalis camb. da Serra da Cantareira/SP. In: Anais do XI Encontro Brasileiro em madeiras e Estruturas de madeiras - EBRAMEM XI, Londrina. pp. 1-9.

Lima, R.S., Oliveira, P. \& Rodrigues, L.R. 2009. Anatomia do lenho de Enterolobium contortisiliquum (Vell.) Morong (Leguminosae-Mimosoideae) ocorrente em dois ambientes. Revista Brasileira de Botânica 32: 361-374.

Longui, E.L., Lima, I.L., Florsheim, S.M.B. \& Bufolo, A. 2009. Variação anatômica radial do lenho de açoita-cavalo (Luehea divaricata) e sua influência na densidade aparente. Revista do Instituto Florestal 21: 181-190.

Longui, E.L. 2009. Potencial de madeiras nativas na fabricação de arcos para instrumentos de corda. Doutorado em Biodiversidade vegetal e meio ambiente. Tese de Doutorado, Instituto de Botânica, São Paulo.

Longui, E.L., Bufolo, A., Aguiar, O.T., Lima, I.L. \& Florsheim, S.M.B. 2009. Anatomia comparada do lenho de Piptadenia gonoacantha (Mart.) J.F.Macbr. em dois tipos de vegetação. Hoehnea 36: 715-724. 
Lorenzi, H., Souza, H.M., Torres, M.A.V. \& Bacher, L.B. 2003. Árvores exóticas no Brasil: Madeireiras, ornamentais e aromáticas. Instituto Plantarum, Nova Odessa.

McCulloh, K.A. \& Sperry, J.S. 2005. Patterns in hydraulic architecture and their implications for transport efficiency. Tree Physiology 25: 257-267.

Marchante, E., Freitas, H. \& Marchante, H. 2008. Guia prático para a identificação de Plantas Invasoras de Portugal Continental. Imprensa da Universidade de Coimbra, Coimbra.

Metcalfe, C.R. \& Chalk, L. 1950. Anatomy of the dicotyledons. v. 2. Clarendon Press, Oxford.

Metzger, J.P., Alves, L.F., Pardini, R., Dixo, M., Nogueira, A. A., Negrão, M. F.F., Martensen A.C. \& Catharino E.L.M. 2008. Características ecológicas e implicações para a conservação da Reserva Florestal do Morro Grande. Biota Neotropica 6: 1-13. http:// www.biotaneotropica.org.br/v6n $2 / \mathrm{pt} /$ abstract?article+bn01006022006 (acesso em 8.01.2010)

Munsell, A.H. 1957. Munsell book of color; defining, explaining and illustrating the fundamental characteristics of color. Munsell Color Company, Baltimore.

Nakata, P.A. 2003. Advances in our understanding of calcium oxalate crystal formation and function in plant. Plant Science 164: 901-909.

Paiva, P. 1997. Pittosporum. In: S. Castroviejo (ed.). Flora Iberica - Plantas vasculares de la Península Ibérica e islas Baleares. v. 5 Ebenaceae - Saxifragaceae. Real Jardín Botânico, Madrid, pp. 1-73.

Panshin, A.J. \& De Zeeuw, C. 1980. Textbook of wood technology. 4 ed. McGraw Hill, New York.

Quilhó, T., Miranda, I. \& Pereira, H. 2006. Within-tree variation in wood fibre biometry and basic density of the urograndis eucalypt hybrid (Eucalyptus grandis $\times$ E. urophylla). IAWA Journal 27: 243-254.

Roque, R.M., Tomazello Filho, M. \& Dias, C.T.S. 2007. Variações na estrutura da anatomia do lenho de árvores de Gmelina arbórea Roxb. (Verbenaceae) de clima tropical seco e úmido na Costa Rica. Scientia Forestalis 75: 65-75.

Roque, R.M. \& Tomazello Filho, M. 2009. Variação radial da estrutura anatômica do lenho de árvores de Gmelina arborea em diferentes condições de clima e de manejo na Costa Rica. Scientia Forestalis 83: 273-285.

Rossi, M., Faria, A.J., Wenzel, R., Câmara, C.D., Arcova, F.C.S., Cicco, V., Ranzini, M., Luiz, R.A.F., Santos, J.B.A., Souza, L.F.S. \& Veneziani, Y. 2009. Avaliação do meio físico. In: Leonel, C. (coord.) Plano de Manejo do Parque Estadual Alberto Löfgren. Instituto Florestal, São Paulo, pp. 69-107.

Santana, O.A. \& Encinas, J.I. 2008. Levantamento das espécies exóticas arbóreas e seu impacto nas espécies nativas em áreas adjacentes a depósitos de resíduos domiciliares. Biotemas 21:29-38.
Sass, J.E. 1951. Botanical Microtechniche. The Iowa State College Press, Ames.

Silva, L.B., Santos, F.A.R., Gasson, P. \& Cutler, D. 2009. Anatomia e densidade básica da madeira de Caesalpinia pyramidalis Tul. (Fabaceae), espécie endêmica da caatinga do Nordeste do Brasil. Acta Botanica Brasilica 23: 436-445.

Silva, L.M., Hasse, I., Moccelin, R. \& Zboralski, A.R. 2007. Arborização de vias públicas e a utilização de espécies exóticas: o caso do bairro centro de Pato Branco/PR. Scientia Agraria 8: 47-53.

Sipinski, E.A.B., Machado, F.S., Toniolo, L.M.G. \& Leme, S. (orgs.). 2009. Um jeito de cuidar da biodiversidade de Curitiba. Cartilha 4. Prefeitura Municipal de Curitiba e Sociedade de Pesquisa em Vida Selvagem e Educação Ambiental, Curitiba.

Suckow, I.M.S., Longui, E.L., Lima, I.L., Florsheim, S.M.B. \& Aguiar, O.T. 2009. Anatomia da madeira e densidade básica de angico-branco Anadenthera colubrina (vell.) Brenan. IF Série Registros 40: 131-135.

Teixeira, B.M. 2008. Variabilidade radial e longitudinal de propriedades da madeira de Angico-vermelho (Anadenanthera peregrina (L.) Speg.). Tese de Doutorado, Universidade Federal de Viçosa, Viçosa.

Testoni, L.N., Longui, E.L., Lima, I.L., Florsheim, S.M.B. \& Melo, A.C.G. 2009. Variação anatômica na madeira de Plathymenia reticulata e sua influência na densidade aparente e velocidade de propagação do som. IF Série Registros 40: 125-130.

Tsuchiya, R. \& Furukawa, I. 2009. Radial variation in the size of axial elements in relation to stem increment in Quercus serrata. IAWA Journal 30: 15-26.

Urbinati, C.V., Azevedo, A.A., Silva, E.A.M. \& Lisboa, P.L.B. 2003. Variação estrutural quantitativa no lenho de Terminalia ivorensis A. Chev., Combretaceae. Acta Botanica Brasilica 17: 421-437.

Van der Graaff, P. \& Baas, P. 1974. Wood anatomical variation in relation to latitude and altitude. Blumea 22: 101-121.

Watson, L. \& Dallwitz, M.J. 1992 onwards. The families of flowering plants: descriptions, illustrations, identification, and information retrieval. Version: 25th November 2008. http://delta-intkey.com'. (acesso em 29.01.2010).

Weber, E. 2003. Invasive plants of the World. CABI Publishing, Wallingford.

Wiemann, M.C. \& Williamson, G.B. 1989. Radial gradients in the specific gravity of wood in some tropical and temperate trees. Forest Science 35: 197-210.

Zanon, B.R., Longui, E.L., Florsheim, S.M.B. \& Lima, I.L. 2008. Variação radial da densidade básica e dimensões celulares de Croton floribundus Spreng. na Serra da Cantareira, SP. IF Série Registros 36: 25-29. 